\title{
A further plea for rigorous science and explicit disclosure of potential conflicts of interest
}

\author{
Rémy Slama $\cdot$ Josef Cyrys $\cdot$ Olf Herbarth $\cdot$ \\ H.-Erich Wichmann · Joachim Heinrich
}

Published online: 21 March 2009

(C) Springer-Verlag 2009

Dr. Morfeld recently published in this journal an editorial listing threats to validity in epidemiologic studies (Morfeld 2009). The threats to validity enumerated included publication bias, exposure misclassification and biased analyses and distorted presentations of epidemiologic studies. To illustrate this last type of bias, Dr. Morfeld took the example of our study of air pollutants and term birth weight in a Munich birth cohort published in 2007 in Environmental Health Perspectives (Slama et al. 2007). These criticisms are unfounded, as we briefly discuss below.

The main criticisms of our study concerned the analysis of birth weight as a binary outcome rather than as a continuous outcome, the numerical stability of the log-binomial

\footnotetext{
R. Slama $(\bowtie)$

Avenir Team "Environmental Epidemiology Applied to Fecundity and Reproduction", Inserm, U823, Institut Albert Bonniot, INSERM and University J Fourier Grenoble Joint Research Center, BP 170, La Tronche, 38042 Grenoble CEDEX 9, France

e-mail: Remy.slama@ujf-grenoble.fr

R. Slama

INSERM and University Joseph Fourier Grenoble,

38100 Grenoble, France
}

\section{J. Cyrys $\cdot$ H.-E. Wichmann $\cdot$ J. Heinrich}

Institute of Epidemiology, Helmholtz Zentrum München, German Research Center for Environmental Health, Neuherberg, Germany

\section{O. Herbarth}

Department Expositionsforschung und Epidemiologie, UFZ, Umweltforschungszentrums Leipzig-Halle, Leipzig, Germany

H.-E. Wichmann

Ludwig-Maximilians University, Munich, Germany models and finally the interpretation of the model adjusted for all atmospheric pollutants simultaneously.

Dr. Morfeld's assertion that, because birth weight is recorded as a continuous outcome, it is most appropriately analysed as a continuous outcome, ignores much of the published work on perinatal outcomes. Indeed, as indicated by Wilcox (2001), "For most of the previous century, birthweight has been treated as a dichotomy." Consistent with the clinical notions of low birth weight and small for gestational age newborn (van Wassenaer 2005), epidemiologists often treat birth weight as a binary outcome, using an arbitrary cutoff (low birth weight) or a cutoff corresponding to a given percentile of the sex- and gestational age-specific birth weight distribution in a reference population (Savitz et al. 2002). Treating birth weight as a continuous outcome is also an option, allowing shifts in entire birth weight distribution associated with exposure to be studied. However, such shifts in the entire birth weight distribution are mostly driven by shifts within the dominant distribution. They may not occur if an exposure only causes an increase in the proportion of births in the lower tail of the birth weight distribution (Savitz et al. 2002), a situation that may be identified by dichotomizing birth weight. For this reason, both approaches should be seen as complementary and are often used in parallel.

We analysed birth weight as a continuous outcome, and did not find an association with maternal exposure to atmospheric pollutants; however, we did observe an association with atmospheric pollutants when we treated birth weight as a binary outcome with a cutoff at 3,000 g (Slama et al. 2007). Due to the limitations on word count and the number of tables imposed by the journal, we could not describe in detail our analysis of birth weight as a continuous outcome, nor state these results in the abstract. However, we clearly stated that we had undertaken this analysis and indicated its 
main finding (that no association was detected). This is in line with current recommendations in epidemiology, advising authors to state the main analyses performed, although the full set of results corresponding to these analyses cannot all be reported in a publication. We do not consider that we presented our findings in a distorted way; this might have been the case if we had not mentioned the continuous analysis. Equally, we do not consider that we should not have undertaken or reported the binomial analysis, which demonstrated associations between atmospheric pollutants and birth weight. On the contrary, not reporting findings of possible relevance to public health could be more problematic than cautiously reporting these findings.

Dr. Morfeld quotes part of a sentence from our article (“...log-binomial models failed to converge.”), misleadingly suggesting that we used statistical models that did not converge. The whole sentence reads: "Since log-binomial models failed to converge, we used a Poisson model (Greenland 2004; Spiegelman and Hertzmark 2005) with a maximum likelihood estimator." There was no problem of convergence with the Poisson model that we used. In the context of cohort or cross-sectional data, the Poisson model yields a more relevant risk estimate than odds-ratios estimated by logistic regression (Greenland 2004; Spiegelman and Hertzmark 2005), making it possible to report results more explicitly.

In contrast to Dr. Morfeld's assertion, our choice to report only the results of the single-pollutant models in the abstract was not driven by the fact that some of these were "significant". Air pollution studies often focus on singlepollutant rather than multi-pollutant models. Indeed, given the relatively high correlation between levels of pollutants sharing common sources, results of models simultaneously adjusted for several pollutants are difficult to interpret and are unlikely to provide a more relevant estimate of air pollution effects than results that are not adjusted for co-pollutants (Kim et al. 2007; Schwartz et al. 2007).

In addition to illustrating that a $P$ value lower than 0.05 is not sufficient for a statistical association to be "true", the article by Ioannidis (2005) quoted by Dr. Morfeld shows that it is misleading to emphasize the statistically significant findings of any single research team; indeed, the overall weight of evidence should be considered. Our article followed on from many other studies reporting associations between atmospheric pollution levels and pregnancy outcomes, the earliest of which was published more than 30 years ago (Williams et al. 1977). These studies have been the subject of several reviews (Glinianaia et al. 2004; Lacasana et al. 2005; Maisonet et al. 2004; Ritz and Wilhelm 2008; Slama et al. 2008; Sram et al. 2005) and have led the WHO to conclude that, "There is evidence that implicates ambient air pollution in adverse effects on pregnancy, birth outcomes and male fertility." (Krzyzanowski et al. 2005). Nonetheless, there are still important areas for improvement in this field, particularly in terms of exposure assessment (e.g. by land-use regression or dispersion models, personal monitoring or use of exposure biomarkers), and identification of potential underlying biological mechanisms, an area where additional toxicological studies (Rocha et al. 2008) would be most welcome. However, the current body of evidence suggests that, in addition to its effects on mortality, respiratory (Morgenstern et al. 2007) and cardiovascular diseases (Peters et al. 2004), air pollution probably also affects pregnancy outcome, in Germany and other industrialized countries.

Given his plea for an undistorted presentation of research findings, it is somewhat surprising that Dr. Morfeld does not mention our effort to enhance research standards in the field of studies on the effects of air pollution on foetal growth. In particular, our exposure model relied on a land-use regression approach based on 40 measurement sites in the city of Munich, yielding a finer spatial resolution than approaches based solely on the air quality monitoring network. Moreover, we could control for key factors influencing birth weight such as maternal smoking, size and weight, limiting the potential for confounding. We are also surprised that Dr. Morfeld failed to report his affiliation to Evonik Industries, a firm that operates power plants, as a potential source of conflict of interest in his editorial (Morfeld 2009) criticizing a study on the effects of air pollution.

Distorted, overstated and oversimplified interpretations may threaten the reputation of epidemiology, but these issues do not apply to our publication. The distorted presentation of published studies by scientists with a non-disclosed potential conflict of interest represents another threat, this time to timely public health decisions aiming to protect the health of human populations (Michaels and Monforton 2005).

Conflict of interest statement The authors declare that they have no conflict of interest.

\section{References}

Glinianaia SV, Rankin J, Bell R et al (2004) Particulate air pollution and fetal health: a systematic review of the epidemiologic evidence. Epidemiology 15:36-45. doi:10.1097/01.ede.0000101 023.41844.ac

Greenland S (2004) Model-based estimation of relative risks and other epidemiologic measures in studies of common outcomes and in case-control studies. Am J Epidemiol 160:301-305. doi:10.1093/ aje/kwh221

Ioannidis JP (2005) Why most published research findings are false. PLoS Med 2:e124. doi:10.1371/journal.pmed.0020124

Kim JY, Burnett RT, Neas L et al (2007) Panel discussion review: session two-interpretation of observed associations between multiple ambient air pollutants and health effects in epidemiologic 
analyses. J Expo Sci Environ Epidemiol 17(Suppl 2):S83-S89. doi:10.1038/sj.jes.7500623

Krzyzanowski M, Kuna-Dibbert B, Schneider J (eds) 2005. Health Effects of Transport-related Air Pollution. Copenhagen: World Health Organization, Regional Office for Europe

Lacasana M, Esplugues A, Ballester F (2005) Exposure to ambient air pollution and prenatal and early childhood health effects. Eur J Epidemiol 20:183-199. doi:10.1007/s10654-004-3005-9

Maisonet M, Correa A, Misra D et al (2004) A review of the literature on the effects of ambient air pollution on fetal growth. Environ Res 95:106-115. doi:10.1016/j.envres.2004.01.001

Michaels D, Monforton C (2005) Manufacturing uncertainty: contested science and the protection of the public's health and environment. Am J Public Health 95(Suppl 1):S39-S48. doi:10.2105/ AJPH.2004.043059

Morfeld P (2009) A plea for rigorous and honest science-false positive findings and biased presentations in epidemiological studies. Arch Toxicol 83:105-106. doi:10.1007/s00204-008-0398-3

Morgenstern V, Zutavern A, Cyrys J et al (2007) Respiratory health and individual estimated exposure to traffic-related air pollutants in a cohort of young children. Occup Environ Med 64:8-16. doi:10.1136/oem.2006.028241

Peters A, von Klot S, Heier M et al (2004) Exposure to traffic and the onset of myocardial infarction. N Engl J Med 351:1721-1730. doi:10.1056/NEJMoa040203

Ritz B, Wilhelm M (2008) Ambient air pollution and adverse birth outcomes: methodologic issues in an emerging field. Basic Clin Pharmacol Toxicol 102:182-190

Rocha ESIR, Lichtenfels AJ, Amador Pereira LA et al (2008) Effects of ambient levels of air pollution generated by traffic on birth and placental weights in mice. Fertil Steril 90:1921-1924. doi:10.1016/j.fertnstert.2008.07.1352

Savitz DA, Hertz-Picciotto I, Poole C et al (2002) Epidemiologic measures of the course and outcome of pregnancy. Epidemiol Rev 24:91-101. doi:10.1093/epirev/mxf006

Schwartz J, Sarnat JA, Coull BA et al (2007) Effects of exposure measurement error on particle matter epidemiology: a simulation using data from a panel study in Baltimore, MD. J Expo Sci Environ Epidemiol 17(Suppl 2):S2-S10. doi:10.1038/sj.jes.7500619

Slama R, Morgenstern V, Cyrys J et al (2007) Traffic-related atmospheric pollutants levels during pregnancy and offspring's term birth weight: a study relying on a land-use regression exposure model. Environ Health Perspect 115:1283-1292

Slama R, Darrow LA, Parker JD et al (2008) Atmospheric pollution and human reproduction: report of the Munich international workshop. Environ Health Perspect 116:791-798

Spiegelman D, Hertzmark E (2005) Easy SAS calculations for risk or prevalence ratios and differences. Am J Epidemiol 162:199-200. doi:10.1093/aje/kwi188

Sram RJ, Binkova B, Dejmek J et al (2005) Ambient air pollution and pregnancy outcomes: a review of the literature. Environ Health Perspect 113:375-382

van Wassenaer A (2005) Neurodevelopmental consequences of being born SGA. Pediatr Endocrinol Rev 2:372-377

Wilcox AJ (2001) On the importance-and the unimportance-of birthweight. Int J Epidemiol 30:1233-1241. doi:10.1093/ije/ 30.6.1233

Williams L, Spence A, Tideman SC (1977) Implications of the observed effects of air pollution on birth weight. Soc Biol 24:1-9 